\title{
In Post-Epidemic Era, the Construction of Chinese Sport Image Influenced by Cosmopolitanism and Nationalism
}

\author{
Chen Yanying \\ PhD in Cultural Studies, School of International Communications, University of Nottingham (China), Ningbo, China \\ Linda931230@126.com
}

\begin{abstract}
With the outbreak and pandemic of Coronavirus disease 2019, professionals from General Administration of Sport of China stated that the Chinese Sport Delegation should positively face it and make preparation at advance. It has been founded that Chinese mainstream media news and social media posts mainly focus on reporting in three dimensions. Firstly, they pay attention on physical and psychological state of Chinese athletes and the influence of delay of the Tokyo Olympics on athletic performance. Then, the internationalization of Chinese sport and the construction of Chinese sport image through online and offline activities of Chinese sport fans are also included in Chinese mainstream media news and social media posts. According to the ideologies of cosmopolitan and nationalism connected with Chinese sport, in post-epidemic era, it is necessary to cultivate young athletes so as to promote national confidence during the internationalization of Chinese sport. While online Chinese citizens actively join in the discussion and construction of Chinese sport image, heathy and positive cyber-nationalism should be promoted. Media professionals can play the role of "opinion leader" in sport virtual community to promote the professionalization of the expressions of cyber-nationalism.

Keywords: Coronavirus disease 2019, Post-epidemic era, Cosmopolitanism, Nationalism related with Chinese sport, Healthy, positive and professional cyber-nationalism
\end{abstract}

\section{后疫情时代，基于世界主义与民族主义理念中国体育形 象建构}

陈妍颖

文化研究博士, 国际传播学院, 诺丁汉大学 (中国), 宁波, 中国 Linda931230@126.com

摘要:

2020 年新冠肺炎疫情世界性的大爆发，中国国家体育总局针对东京奥运会延期决定召开研讨大会多位 专家表明, 应做到积极应对, 未雨绸缪。研究发现后疫情时代中国主流媒体与自媒体报道主要聚焦关 注三个方面：关注东京奥运会延迟对中国运动员竞技状态的影响、关注中国体育国际化之路与体育实 力提升、体育产业线上线下联动，网民成为体育形象建构参与者。基于世界主义与中国体育民族主义 理念, 后疫情时代, 加速中国形象世界化的过程中需培养本土化年轻运动员等手段提升中国体育民族 主义与本国的民族自信。网民积极参与中国体育形象的讨论, 需培养健康、积极向上的网络民族主义, 专业媒体人可成为体育超话社区里的“意见领袖”，并促进网络民族主义情感的表达专业化。 关键词: 新冠肺炎疫情, 后疫情时代, 世界主义, 中国体育民族主义, 健康、积极与专业的网络民族 主义

1. 前言

2020 年新冠肺炎疫情世界性的大爆发, 造成了经
济、体育、文创等产业不可估量的损失，特别是疫情严 重的国家及地区，国际体育赛事、国家体育俱乐部赛事 相继停摆，如环意、法网、F1、NBA、五大联赛等国际 赛事相继延期，甚至有取消赛季余下赛事的趋向。突入 
袭来的 “体育寒冬”, 给职业联赛俱乐部带来了前所未 有的压力, 迫于商业运营的压力, 诸多俱乐部正大量裁 员。已被世界卫生组织（WTO）认定为 “大流行” 的新 冠肺炎疫情, 截至 2020 年 4 月底, 世界 200 余个国家 与地区的国民深受其害, 超过 100 万人感染新冠肺炎。 东京当地时间 4 月 28 号, 东京奥组委主席表示, 若 2021 年新冠肺炎疫情仍然得不带控制, 原定 2021 年 7 月举 行的东京奥运会将取消，据文汇报消息称，东京奥运会 延期举办额外成本超 3000 亿日元。此外，日本权威传 染病学家北村义浩认为, 明年如期举办奥运会的可能性 为 0 。他在接受日本媒体采访时表示, 除非出现疫苗或 其他治疗药物, 限制新冠疫情的发展, 但这不能仅靠日 本一个国家的努力 $[9]$ 。

尽管日本奥组委主席与权威传染病学家提出东京 奥运会在 2021 年举办的风险与不确定性, 中国国家体 育总局针对东京奥运会延期决定召开研讨大会, 多位体 育领域专家学者、资深媒体人表明，“我国应密切关注 东京奥运会延期对运动员、教练员造成的心理影响, 最 忌备战心态由紧绷而突然松弛，或因延期而导致焦虑” [3], 应做到积极应对, 未雨绸缪。南京体育学院院长 杨国庆表示, 我国传统优势项目譬如蹦床、体操、羽毛 球等, 已进入新老运动员交替期, 17 个项目中 30 岁以 上运动员达 31 人, 老运动员伤病增多, 他们能否延续 巅峰时期的竞技状态? 能否保持传统夺金项目曾经的 优势? 都成为奥运延期后国家体育代表团担忧的问题。 新冠肺炎疫情肆虐全球, 导致原定于 2020 年举办的东 京奥运会延期一年举办, 甚至有取消举办的风险, 作为 世界体育强国之一的中国, 面对东京奥运会延期所带来 的重大影响, 中国体育产业的变化与中国体育形象建构 值得研究, 研究成果对后疫情时代中国体育产业发展改 革具有重要借鉴意义 [8]。

\section{2. 东京奥运会延期影响下的中国体育产业}

国际奥委会委员会丹尼・庞德 (DickPound) 当地时 间 3 月 23 日正式宣布, 原定于 2020 年 7 月举办的东 京奥运会将延期举办。新冠肺炎疫情肆虐全球，奥运会 延期, 多国体育职业联赛停摆, 体育产业正经历着后疫 情时代的挑战与变革。本研究抽取 2020 年 4 月（东京 奥运会正式宣布延期一个月）人民日报每日 “体育要闻 排行榜” 前十五的体育新闻文本，与 2020 年 4 月新浪 微博体育类超话社区阅读量排行第一的 “体育”超话社 区所有推文，作为内容分析的研究文本。针对近 1000 条新闻文本与推文的主题进行归类, 东京奥运会正式宣 布延期后一个月内, 中国官方主流媒体与自媒体主要从 以下几个角度再现中国体育产业:

\section{1 关注东京奥运会延迟对中国运动员竞技 状态的影响}

东京奥运会延迟，加上 2020 年新冠肺炎疫情影响
下诸多国际体育赛事延期举行，意味着 2021 年运动员 们的参赛日程更加紧密。密集参赛对运动员们的体能以 及心理状态是个极大的挑战, 特别是几个传统夺金项目 的老将们需要推迟一至两年退休。国家体育总局体育科 学研究所体育社会科学研究中心研究员邱雪认为, “随 着东京奥运会延期,一定程度上会对我国运动员的备战 节奏带来改变, 因此需要及时调整应对。对于一些年龄 偏大的运动员，他们的竞技状态能否保持到明年举行奥 运会时，甚至能否继续参赛，是摆在他们面前的现实问 题。” (3)奥运冠军马龙, 丁宁, 刘诗雯, 37 岁的 “高龄” 林丹, 33 岁的中国女排主要的间妮, 36 岁的奥运举重 冠军吕小军, 行走 33 岁的奥运冠军刘虹, 花样游泳世 锦赛亚军黄雪辰 30 岁, 已过运动黄金年龄的老将们, 仍然被国家给予夺金厚望。后疫情时代开启，东京奥运 会备战进入新的一轮挑战期, 老将们需要在保证良好身 心健康前提下, 适当训练保持体能与竞技状态, 重点夺 金项目老将们的竞技状态成为媒体和体育观众们关注 的热点之一 $[4]$ 。

此外,在关注中国运动员备战东京奥运会竞技状态 同时，人民日报与 “体育” 新浪微博超话社区多条推文 提及国家需要调整体育人才培养战略。在东京奥运周期 的备战中, 中国竞技体育出现整体竞争力下滑的态势, 尤其是传统的六大夺金项目老将需要延长运动周期 (乒 乓球、羽毛球、跳水、举重、射击、体操), 老将们的 竞技状态不确定性与年轻人才匮乏已成为困扰中国竞 技体育的难题。2020 年 4 月中国境内新冠肺炎疫情已 得到稳定控制后, 备战东京奥运会的运动员们开始恢复 训练, 既要保证老将们的身心健康与竞技状态恢复, 又 要大力提升与培养年轻的运动人才能增添中国体育产 业的活力, 已成为后疫情时代中国体育产业不可忽视的 人才培养战略。

\section{2 关注中国体育国际化之路与体育实力提 开}

东京奥运会正式宣布延迟举办后,主流新闻媒体与 自媒体除了关注中国本国运动员的竞技状态, 从宏观角 度洞察中国体育产业的发展, 特别是中国体育实力的提 升途径与体育国际化发展之路。东京奥运会备战周期的 延长, 意味着 2020 年下半年至 2021 年中国运动员将 要面临密集的国际大赛赛程, 新闻报道涉及各传统强项 中国队的实时备战状态, 与他国国家队热身赛训练赛等 报道。同时也关注在海外效力的中国运动员身心健康与 竞技状态, 以及后疫情时代中国体育产业外援引进状况 譬如中国足坛对 “归化球员” 政策变化。新冠肺炎肆虐 欧洲，中国球员武磊不幸感染新冠肺炎，且由于经济形 势惨淡导致俱乐部资金周转困难，武磊暂时面临失业。 自 2 月底新冠肺炎疫情在欧洲爆发后,武䂞感染新冠肺 炎疫情直至康复出院恢复性训练, 主流媒体和自媒体均 密切跟踪报道武否的身心健康与降薪等。对于武否暂时 性失业，新闻媒体报道中透露出足够的信心，鼓励在海 外职业俱乐部效力的中国球员重新树立信心, 在欧美激 
烈的竞技体育竞争中提升个人实力, 促进中国与世界各 国体育产业的交流与融合。全球化进程加速后, 体育人 才交流已成为普遍现象，2019 年起中国足联加大 “归 化球员” 的引进力度, 即鼓励有华裔血统的外籍球员加 入中国国籍, 为中国国家队或中超俱乐部效力。中超恒 大足球俱乐部加大引进 “归化球员” 的力度，中国国足 引进“归化球员”备战 2022 年卡塔尔世界杯预选赛等, 中国足球产业国际化发展变革与 “归化球员” 相关的新 闻故事, 已成为主流媒体与自媒体新闻排行榜中重大议 题之一。

不同国家之间关于体育发展的互动与竞技,球员出 国发展, 球员交易等, 是体育产业国际化之路的重要组 成部分, 即体育研究学者康昌发教授提到的 “体育国际 化” 第一层内涵 “沟通观”, 国家与国家之间在体育相 互交流、相互沟通，通过找寻各国体育差异之所在，求 同存异，以便更好地加强体育的国际交往。同时，康昌 发教授还提到 “体育国际化” 另外两个重要内涵，“协 调观”与 “统一观” 尽量减少不同国家之间体育交流的 差异性、冲突与矛盾 [5]。后疫情时代, “体育国际化” 依旧是一个动态过程, 体育研究学者薛来何提到, 在体 育国际化过程中, “需要通过以专业化带动多元化、进 行专业性调查分析、培养本土化人才等手段, 最大限度 地提升我国体育产业竞争力” [10]。在体育国际化进程 中, 稳固传统强项在国际上的优势地位, 希望中国体育 代表团参与国际赛事展现出强大的综合实力, 鼓励有实 力的中国本土运动员 “走出去”, 用开放的心态接受学 习世界各国的优势体育文化，同时也更新政策便于引入 海外球员为中国体育产业注入多元体育文化。

\section{3 体育产业线上线下联动，网民成为体育形 象建构参与者}

全球新冠肺炎疫情肆虐下, 东京奥运会和其他国际 体育赛事纷纷延期或停摆, 线上健身直播、“云健身” 的 推广达到了新高度。人民日报推出了新栏目 “居家 动起来”, 新浪微博出现 10 个 “云健身” / “健身直播” 话题讨论区阅读量均超过 20 万。“云健身” / “健身直 播” 即线下健身运动转化为线上健身教练直播, 受众参 与互动并在自己所处的空间里参与健身文化。

2018 年中国体育学者石岩发现，在体育消费需求 升级带动作用下, 用户的体育消费方式爱是转变。随着 社交媒体在大众生活中的日益渗透, 大众运动休闲消费 需求开始强调 “休闲社交体验” 的综合性，可根据不同 用户的消费需求对社交媒体科技进行创新 [6] [7]。新 媒体科技引发的短视频热潮与大众休闲运动、健身文化 的结合, 由短视频带动大众参与健身文化, 并给予大众 自由发挥利用新媒体科技创造新的健身文化的空间。后 疫情时代, 由于国际赛事的停摆以及线下体育活动受阻, 又掀起了一波 “云健身” / “健身直播”热潮, 居家运 动与线上社交互动结合的新型健身方式的推行, 在中国 体育产业中衍生出新的大众运动休闲方式。疫情影响下 的中国体育产业研究, 不仅仅局限于对中国体育代表团
运动员备战状态的关注以及对中国体育产业国际化之 路的反思, 不少新闻报道与学术研究涉及网民参与 “云 健身” / “健身直播” 的动机与满足感等。国家体育总 局最新的统计数据显示, 知名教练员和运动员制作的科 学健身视频在互联网平台上的累计播放量已超过 26 亿次，其中不少用户为 “云健身” 的忠实参与者，不但 积极地与健身教练互动, 还录制自己健身打卡视频在线 上传, 引发线上对于中国健身文化甚至中国体育更加多 元化的讨论。因此社交媒体互动体验与线上健身文化的 结合，促进网民成为中国体育形象的建构者，线上线下 联动为中国体育文化注入更多科技创新的元素。

\section{3. 后疫情时代, 基于世界主义与民族主义的 中国体育形象建构}

后疫情时代, 中国的主流媒体与自媒体对于中国体 育形象的报道主要聚焦在三个方面, 东京奥运会延迟对 中国运动员竞技状态的影响, 中国体育国际化之路与体 育实力提升以及“云健身”热潮助力中国体育形象建构。 体育学者康昌发曾提出, 中国建构体育形象增强体育实 力的同时, 需要加快体育国际化进程。“体育的国际化 有利于促进国际经济往来和体育国际间的交流; 有利于 全球经济的高速发展; 有利于加强对跨国体育产业活动 的理解和管理; 有利于世界体育水平的提高。同时, 体育 的国际化不仅是体育管理者和体育信息外部使用者的 要求, 而且也是众多国家体育内部发展的需要。” [5]

中国体育产业的国际化进程, 即面向世界各国再现 中国体育形象, 并促进人类共同体的形成。正如社会学 学者张有奎所论述, “人类命运共同体的新构想积极建 构了全球化时代人类交往的新范式, 为人类的光明未来 提供了一种现实可能性，对于人们突破个体本位主义， 思考人与自然人与人、人与自我的关系”, 对于世界 不同国家之间的连结具有重要意义 [12] [13] [2]。后 疫情时代全球化日益加剧, 面向世界各国展现中国体育 形象，即推行 “文化世界主义”与 “消费世界主义” 的 过程。政治学家蔡拓曾提到, “文化世界主义” 即认为 “文化领域始终处于变动之中, 所以要在文化的变动中 不断选择、修正、重塑文化诉求与倾向, 不要固守一种 特定的文化”，从世界多元文化与本国文化关系此维度 来解读 “文化世界主义” 的内涵，即 “坚持世界主义视 角下的多元文化, 反对排他性的文化边界与文化身份固 定论的主张” [1]。“文化世界主义” 既保护世界文化的 多元色彩, 也能够帮助中国体育形象不断修正加速国际 化进程, 避免固守本国文化阻碍国际化发展。同时, 蔡 拓强调了“消费世界主义” 的重要性, 霍尔特曾指出, “由于世界主义导致了社会地位和文化资本的多样性, 消费者往往希望变成世界主义者。希望获得较多文化资 本的消费者逐渐形成世界性的品味, 这种品味可能体现 为对起源于他国且异于本国的音乐、文化以及其它产品 的消费。” [1] “消费世界主义” 的兴起, 能够带动中 国体育形象获得更多他国体育粉丝的高度认可, 带动他 国体育粉丝接受中国体育形象并致力于打造世界认可 
的体育消费产物。

然而, 面向世界建构中国体育形象并推行 “文化世 界主义”与 “消费世界主义”的同时，也需要关注体育 形象与本国民族主义的相关性。体育学者余捷强调全球 化进程中, 中国体育形象塑造与体育民族主义的相关性, “全球化、世界主义理念影响下，跨国资本试图消融文 化边界，并整合不同地区的文化差异。资本消解了民族 认同, 转化这些混杂的文化认同, 使得曾经被视为具有 抵抗全球同质化可能性的体育民族主义, 反而加速了全 球同质化的过程” [11], 譬如代表中国体育形象的网球 运动员李娜、中国篮球运动员姚明，承载 “世界化的体 育民族主义”的价值。但余捷也提到，代表中国体育形 象的人物如姚明、林书豪等，也塑造了中国社会依附于 中国籍运动员身上的民族自信与认同, 不同于西方语境 下的体育民族主义，因此引发了全球化、世界主义理念 影响下体育民族主义的反思, 以及世界主义与民族主义 交织下中国体育形象建构 [11]。

\section{4. 后疫情时代, 完善中国体育形象建构的路} 径

\section{1 推行世界主义与中国体育民族主义融合}

全球化进程加速过程中，“文化世界主义”与 “消 费世界主义” 的推行逐渐将具有中国特色的体育文化, 转化为世界公民社会共同的消费产物与文化资本, 加速 中国体育形象世界化, 在认可与消费中国体育形象的同 时形成了世界化的民族主义。但后疫情时代, 诸多国际 体育赛事停摆的现状, 对中国体育代表团运动员的训练 状态与备战国际赛事的状态产生一定程度的消极影响, 譬如世界知名运动老将们需要推迟退役年龄与重新开 启奥运会备战。在国际赛事的空窗期, 在保证世界知名 运动老将们征战世界大赛的状态同时, 应致力于维护中 国体育形象在国际上的影响力, 即中国体育形象建构对 世界化民族主义情感的积极作用。世界化民族主义情感 形成过程中, 不断反思与重构中国体育形象, 应将本土 化与世界化结合, 培养本土化年轻运动员等手段提升中 国体育民族主义与本国的民族自信。

\section{2 促进健康、积极向上与专业化的网络民族 主义情感表达}

后疫情时代，东京奥运会延期至 2021 年以及其他 国际赛事、职业联赛停摆, 公民的运动休闲形式由线下 为主转化为线上 “云健身” / “健身直播”、新浪微博 的体育超话社区等运动与社交相结合的生活体验, 网民 特别是运动爱好者们在 “云健身” / “健身直播”、新 浪微博 “体育超话社区” 等虚拟空间里成为表达言论、 自我呈现的主角, 与中国国家体育代表团运动员一样, 都是中国体育形象的典型代表。新冠肺炎疫情影响下,
新浪微博的体育超话社区里关注度最高的几个话题为 东京奥运会延期对中国奥运代表团的影响、中国球员武 否在欧洲职业联赛的发展之路、疫情影响下归化球员引 入中国的合理性, 关注度高的话题均涉及中国运动员的 海外发展以及中国体育产业的国际化发展之路反思, 均 渗透着网民们对本国的民族自信以及对中国体育形象 建构的反思。后疫情时代网民参与 “云健身” / “健身 直播” 线上社群互动、新浪微博 “体育超话社区” 对于 中国体育形象的讨论, 需培养健康、积极向上的网络民 族主义，网民作为网络民族主义的参与者，依附民族自 信对中国体育形象建构做出集体化的回应。就职于主流 媒体的专业媒体人可深入网络体育讨论社群譬如新浪 微博的体育超话社区, 专业媒体人可成为体育超话社区 里的 “意见领袖”, 带动社群里网民对中国体育形象建 构相关热点事件的评论动态, 并促进网络民族主义情感 的表达专业化，即尊重体育新闻故事的客观性、敢于接 受批判等记者专业素养在参与网络民族主义表达过程 中的体现。

\section{5. 结论}

后疫情时代，东京奥运会延期以及国际赛事停摆， 东京奥运会延迟对中国运动员竞技状态的影响、中国体 育形象国际化以及网民线上线下联动参与中国体育形 象建构，成为中国体育产业的焦点。在世界主义与民族 主义理念影响下, 后疫情时代的中国体育形象建构需兼 顾中国体育发展现状与未来的国际化发展可能性, 推行 中国体育文化世界话的同时,培养本土化年轻运动员等 手段提升中国体育民族主义与本国的民族自信。网民作 为网络民族主义的参与者, 关注中国体育形象国际化建 构, 主流媒体从业者可深入社交媒体体育社群, 促进健 康、积极向上与专业化的网络民族主义情感表达。

\section{REFERENCES}

[1] Cai.T.(2018). The classification of cosmopolitanism. Journal of International Review,2018 (1).

[2] Gong, Z.W.\& Liu, X. (2020). China's Sports Governance Strategy Based on the Concept of a Community of Human Destiny during the Epidemic of COVID-19. Journal of Sport Research, 34(2): 34-40.

[3] Hubei Sport (2020). The measurement of policies for facing the delay of Tokyo Olympics in seminar held by General Administration of Sport of China. http://news.hbtv.com.cn/hbshpd/p/1829101.html

[4] Huang, H.Y \& Liu, W.Y. (2020). The Impact of COVID-19 on Sports Event Development. Journal of Sport Research, 34(2): 51-58.

[5] Kang, C.F, Ouyang, L.Q. \& Yang, M. (2002). 
Considerations about the internationalization of Chinese sport. Journal of Xi'an Institute of Physical Education, 2002(9): 2-6.

[6] Liu, D.F. \& Fu, G.Q. (2020). A Study on the Influencing Factors of the Continued Use Willingness of Online Fitness Service Users During the Epidemic of COVID-19. Journal of Sport Research, 34(2): 41-50.

[7] Shi, Y., Shi, C. \& Wu, C. L. (2018). The Innovation of Fitness and Leisure Service Industry Against the Backdrop of Consumption Upgrade in China. Journal of Sport Research, 1(2): 63-71.

[8] Taihang Development Research Institute (2020). The influence of COVID-19 on sport economy. http://thzk.hpu.edu.cn/taihweb/memo.aspx?id=6898

[9] Wenhui Newspaper (2020). The delay of Tokyo Olympics.

http://www.whb.cn/zhuzhan/yd/20200428/343966.html

[10] Xue,L.K.(2018).The research on the development of Chinese sport industry in the context of the internationalization of sport. Journal of Changchun Normal University, 37(8):121-123.

[11] Yu, J. \& Wang, B.C. (2015). Sport news reportage and the representation of nationalism. The Press, 2015 (24): 119-120.

[12] Zhong, B.S, Huang, Z.J et al. (2020). The Dilemma and Response: Focusing on the Impact of COVID-19 on Sports. Journal of Sport Research, 34 (2): 9-40.

[13] Zhong, B.S. (2020). The Construction of China's Sports Diplomacy Strategy Guided by the Community of Shared Future for Mankind. Sports Culture Guide, 2019 (2): 15-21. 